\title{
The relationship between profit and risk, and the side effects of the orthopaedic treatment
}

\section{G Le Blay}

Address: Centre medico-chirurgical et de réadaptation des Massues Lyon, France

Email: G Le Blay - g.le-blay@cmcr-massues.com

from 6th International Conference on Conservative Management of Spinal Deformities Lyon, France. 21-23 May 2009

Published: I4 December 2009

Scoliosis 2009, 4(Suppl 2):O39 doi:I0.II86/1748-7|6I-4-S2-O39

This abstract is available from: http://www.scoliosisjournal.com/content/4/S2/O39

(c) 2009 Le Blay; licensee BioMed Central Ltd.

\section{Background}

The orthopaedic treatment by thermoformed material is often a long treatment process, and although there is not a contraindication in this type of treatment, there are many known side effects. It is important to present to the patient the framework of the information about the treatment, including the various unwanted effects which he may meet $[2,3]$.

\section{Results}

A Cochrane analysis of existing data on corsets was published in 2008, but only 7 studies on prevention and 8 studies of treatment were analyzed in terms of the effect of this treatment on pain. The conclusions were not made by analysis of data concerning the tolerance or the possible side effects connected to wearing the brace. Biot indeed brings back the history of the orthopaedic treatment Lyonnais which developed in the mid 1950s with Stagnara. He explains the indications and details regarding treatment with plaster for a month followed by a brace for 6 months. He presents the results obtained by various treatment centers. Finally, he describes the following possible complications:

-Rare, but most serious is the cast syndrome which can arise during a circular plaster cast application. It involves a gastric draining by probe before the removal of the brace

-Pulmonary complications, including a collapsed lung, can be provoked by a cast that is too stiff preservation on a major kypho-scoliosis.
-A possible destabilization of the abdominal internal organs (hernia, cystocele).

-Vasculo-nervous injury can also occur (lower limbs stasis, compression of the femoro-cutaneous nerve).

- Breast injury can occur from casting.

- Cutaneous injuries at pressure points, with erythema, tanning of the skin which can be irreversible, ulceration, bursitis, and finally microbial infections can occur.

- Psychological and aesthetic problems also occur.

In this abstract we report the results of over 50 braces worn more than 6 months and we present the side effects reported by the patients. 